\title{
Building Trust in E-Learning
}

\author{
By Y. Diana Wang *
}

\begin{abstract}
As Web-based course delivery continues to emerge and thrive as a legitimate alternative to classroom instruction, educational institutions and online instructors face the challenge of building and sustaining student trust in e-learning. The present study represents an attempt to address the challenge by identifying the social and technical factors that can likely induce or influence students' perception about the trustworthiness of an e-learning course and integrating the factors into a socio-technical framework that can be empirically validated. The methodology used and the data obtained from a university-wide survey conducted in an American university are reported in this paper. The results indicate that two underlying dimensions, Course Instruction and Privacy and Security, exist among the 12 trust-inducing factors. Although all 12 factors were found to contribute to the respondents' perception of the trustworthiness of an e-learning course, the Course Instruction dimension was rated about 10\% higher than the Privacy and Security dimension. This suggests that the social and course design factors (e.g., reputation, design quality, instructor sociocommunicative style), when used effectively, can help overcome students' privacy and security concerns for an e-learning course. The study makes at least two important contributions to the field by proposing a framework of 12 trust-inducing factors for e-learning and by extending the confirmatory factor analysis (CFA) to a new application area of trust evaluation in e-learning.
\end{abstract}

\section{Introduction and Background}

The advancements in information and telecommunications technology have fundamentally transformed Distance Education (DE) from correspondence schools in late 19th century to today's e-learning, which is predominated by the application of Internet technologies. E-learning is defined as 'the delivery of education (all activities relevant to instructing, teaching, and learning) through various electronic media' (Koohang \& Harman, 2005, p. 77) and is also used interchangeably as Web-based instruction, Internet-based training, or online education.

Although a growing number of educational institutions in higher education, within the United States in particular and around the world in general, have invested heavily in Internet technologies and infrastructures to

${ }^{*}$ Associate Professor, George Mason University, USA. 
support e-learning, the majority of postsecondary students are still hesitant about taking online courses, especially for the purpose of earning a virtual degree (Hashem, 2011). Furthermore, according to the 2012 Sloan Survey of Online Education, based on responses from more than 2,800 colleges and universities in the United States, nearly ninety percent $(89.7 \%)$ of the surveyed academic leaders have identified lower retention rates for online courses as a barrier to the widespread adoption of e-learning (Allen \& Seaman, 2013).

From the student's perspective, the decision to take an online course is not an easy one to make: The student must overcome the fear of potentially wasting time and money, disclosing sensitive information, and losing submitted work, and they must take such risks in the absence of face-to-face interactions. Previous research shows that trust is vital for ensuring effective commitments and reducing the level of uncertainty (Kramer, 1999; Luhmann, 2000). Trust is the 'firm belief in the competence of an entity to act dependably, securely and reliably within a specific context' (Grandison \& Sloman, 2000, p. 4). If prospective students are trusting, they are more likely to enroll in online courses, thereby easing enrollment problems; if current students are trusting, they are less likely to drop out, thereby easing retention problems (Ghosh et al., 2001). In addition, as a student's trust in a teacher determines the degree to which that student will be open to being taught by that teacher, trust is also a requisite component of a student-teacher relationship for maximal learning to occur (Wooten \& McCroskey, 1996). Therefore, building and maintaining students' trust in online courses is crucial to the success and future of e-learning.

Despite the fact that trust with all of its connotations has been studied in numerous disciplinary fields, such as philosophy, psychology, management, and marketing (Wang \& Emurian, 2005), there is an apparent dearth of literature on investigating trust in the context of e-learning or understanding its antecedents or determinants thoroughly. The majority of studies that provide models and principles for building trust are in the field of e-commerce and focus on how to promote consumer trust in Internet shopping (e.g., Cheung \& Lee, 2006; Ha \& Stoel, 2009; Jarvenpaa et al., 2000). In recent years, there have appeared a number of studies at the intersection of trust and e-learning, but the focus of the research is limited to either students' trust and perception towards e-learning systems and information security (e.g., Hashem, 2011; Liu $\& \mathrm{Wu}, 2010)$ or the role that trust plays in promoting virtual teams and online collaboration (e.g., Al-Ani et al., 2013; Casaló et al., 2008). Therefore, a pressing need exists for a deeper and more comprehensive understanding on the factors that influence student trust in e-learning. Without such understanding, it is difficult to build and manage student trust in an online environment, thereby making it more challenging for educational institutions and instructors to provide trustworthy, sustaining, and successful online courses.

This paper aims to fill the gap of lacking research by providing a sociotechnical framework of trust-inducing factors based on existing literature on enhancing student trust in e-learning and empirically validating the proposed 
framework through a survey conducted within an American university. In this study, student trust in an e-learning course is defined as 'the degree to which a student is willing to rely on the e-learning system and has faith and confidence in the instructor or the educational institution to take appropriate steps that help the student achieve his or her learning objectives.' This definition is consistent with the concept of trust found in the education literature (Bulach, 1993; Ghosh et al., 2001).

The rest of the paper describes the proposed socio-technical framework, the research methodology, the results of the survey, and, finally, ends with conclusions and directions for future explorations.

\section{Proposed Socio-technical Framework of Trust-inducing Factors}

As the result of a comprehensive literature search and review, a sociotechnical framework of trust-inducing factors is proposed in an effort to synthesize existing literature on enhancing student or consumer trust in virtual environment. The framework is 'socio-technical' because it includes both social and technical features of an e-learning course (including its instructor and the system on which the course is built) that can likely induce or influence students' perception about the trustworthiness of an e-learning course. The framework is not exhaustive in the sense that it does not attempt to capture every possible trust-inducing factor that can be applied in an e-learning course. It is focused on articulating the most prominent set of trust-inducing factors derived from numerous previous studies and presenting them as an integrated entity that can be evaluated empirically.

The framework classifies 12 trust-inducing factors into four broad dimensions: namely, (1) credibility, (2) design, (3) instructor sociocommunicative style, and (4) privacy \& security. The dimensions are identified on the basis of a semantic and functional grouping of factors obtained from the literature. Table 1 illustrates the framework in detail, including the dimensions, trust-inducing factors, and literature sources for each dimension.

Specifically, the Credibility dimension refers to the cognition-based features, such as previous experience or reputation of the e-learning system and the instructor, which are usually formed prior to the current course; The Design dimension defines the overall design quality and accessibility of the informational and graphical components of the e-learning system; The Instructor Socio-Communicative Style dimension refers to the patterns of communication and interaction behaviors of the instructor; And the last dimension, the Privacy and Security dimension relates to the privacy and security measures that can be included in the e-learning system. 
Table 1. A Socio-technical Framework of Trust-Inducing Factors in E-learning

\begin{tabular}{|c|c|c|}
\hline Dimensions & Trust-Inducing Factors & $\begin{array}{c}\text { Literature } \\
\text { Sources }\end{array}$ \\
\hline Credibility & $\begin{array}{l}\text { Prior positive experience with the e- } \\
\text { learning system or the instructor } \\
\text { - Good reputation of the e-learning } \\
\text { system or the instructor }\end{array}$ & $\begin{array}{l}\text { Anwar \& Greer } \\
\text { (2012); Song \& } \\
\text { Zahedi (2007); }\end{array}$ \\
\hline Design & $\begin{array}{l}\text { High information and design quality of } \\
\text { the e-learning system } \\
\text { - Good accessibility and usability of } \\
\text { content and tools in the e-learning } \\
\text { system } \\
\text { - Display of contact details of the } \\
\text { instructor or the physical entity behind } \\
\text { the e-learning system }\end{array}$ & $\begin{array}{l}\text { Bansal, Zahedi, \& } \\
\text { Gefen (2008); } \\
\text { Nikolaou \& } \\
\text { McKnight (2006); } \\
\text { Jaeger \& Xie } \\
\text { (2009); }\end{array}$ \\
\hline $\begin{array}{l}\text { Instructor Socio- } \\
\text { Communicative } \\
\text { Style }\end{array}$ & $\begin{array}{l}\text { - Assertiveness of the instructor } \\
\text { - Responsiveness of the instructor } \\
\text { - A sense of care and community created } \\
\text { by the instructor }\end{array}$ & $\begin{array}{l}\text { Wooten \& } \\
\text { McCroskey } \\
\text { (1996); Curzon- } \\
\text { Hobson (2002); }\end{array}$ \\
\hline $\begin{array}{l}\text { Privacy \& } \\
\text { Security }\end{array}$ & $\begin{array}{l}\text { Disclosure of understandable and } \\
\text { adequate privacy and security policy } \\
\text { statement } \\
\text { Use of security mechanisms (e.g., the } \\
\text { secure HTTP protocol, encryption, } \\
\text { secured logging system, etc.) } \\
\text { Compliance with third-party privacy } \\
\text { assurance or standard (e.g., US-EU \& } \\
\text { US-Swiss Safe Harbor Frameworks, } \\
\text { IEEE LTSC, etc.) } \\
\text { Reliable and timely access to the e- } \\
\text { learning system }\end{array}$ & $\begin{array}{l}\text { Akhter et al. } \\
\text { (2009); } \\
\text { Bansal, Zahedi, \& } \\
\text { Gefen (2008); } \\
\text { Raitman et al. } \\
\text { (2005); }\end{array}$ \\
\hline
\end{tabular}

\section{Methodology}

Survey

A Web-based survey was conducted to confirm the proposed framework of trust-inducing factors. To collect a sample that represents the point of view from the students, or the users of e-learning, in higher education, the link to the survey was distributed to students in a four-year university in the U.S. through various methods, including university listservs, online announcements, and faculty's Twitter posts. To encourage participation, twelve \$25 Barnes and Noble Gift Cards were used as incentives given to winners of a random drawing from the survey respondents. The data collection was anonymous with respondents' express consent (by reading the Informed Consent Form and checking the Consent checkbox to proceed to the next Web page of the survey). The respondents also understood that their personal information (i.e., university email address and ID) would not be linked to their submitted 
answers if they wanted to be included in the prize drawing by entering their personal information on a separate Web page after completing the survey.

The initial survey was first reviewed by four student counselors and one language expert for accessing consistency, completeness, and readability. The objective of this step was to examine the face validity of each item in the survey. As a result, several items were reworded to improve readability and clarity.

The resulting survey is described as follows. After the aforementioned Informed Consent Form, the first section of the survey consisted of four radiobutton groups gathering demographic information on a respondent's class level, gender, weekly hours spent on the Internet, and experience with taking an e-learning course. The second section of the survey included 12 items to rate, which corresponded to the 12 trust-inducing factors in the proposed framework. Respondents rated each item using a 10-point Likert-type scale, which allowed them to select a response indicating the trust-inducing importance of each factor. The scale anchors ranged from ' 1 ,' representing that the factor was 'not important at all,' to '10,' indicating that the factor was 'extremely important.' The third section consisted of four questions that are only relevant for students with disabilities. The last section of the survey was a feedback box providing for comments. As mentioned previously, if the respondent wanted to be included in the prize drawing, he or she can provide personal information on a separate Web page following the survey.

\section{Respondents}

Although 398 students responded to the Web-based survey, a total of 361 respondents were included in the final analysis; the other 37 students were eliminated due to incomplete submissions. Among the included respondents, 170 students (47\%) were female, and $243(67 \%)$ students reported that they had taken an e-learning course. Most of them were undergraduate students ( $\mathrm{n}=$ $221,61 \%$ ), and the rest were graduate and doctoral students. The very majority of the respondents were experienced with the Internet $(n=325,90 \%$ spent more than 10 hours per week online; $n=216,60 \%$ spent more than 20 hours per week online).

\section{Statistical Analyses and Results}

The data analysis had two parts: (1) validating the proposed framework of trust-inducing factors and confirming the underlying dimensions; and (2) evaluating the magnitudes of the ratings across the confirmed dimensions.

\section{Validating the Proposed Framework}

As the initial classification of the four dimensions was based on the author's informed judgment by applying a semantic grouping of the factors obtained from the literature, the 12 trust-inducing factors were subjected to a 
confirmatory factor analysis to assess the construct validity and internal reliability of the constructs. Confirmatory factor analysis (CFA) is a powerful statistical tool for examining the nature of and relations among latent constructs, e.g., attitudes, traits, intelligence, clinical disorders (Jackson et al., 2009). In the current study, it was used to validate the trust-inducing factors and determine the essential dimensions of the identified factors. Before a CFA could be applied, however, two tests that indicated the suitability of the data for structure detection must be ran: The extremely high value $(0.908)$ from the Kaiser-Meyer-Olkin test, which measures sampling adequacy, indicated that a factor analysis would be useful with the data. The significant Bartlett's test $(\mathrm{p}<$ 0.001), which examines whether the variables are related, indicated that the data were suitable for structure detection. Therefore, a CFA was performed.

The principal components analysis was used to analyze the raw matrix of 361 responses with the latent root criterion (eigenvalue $=1$ ). Surprisingly, there were only two components with eigenvalues greater than 1 (i.e., eigenvalue $=$ 6.65 and eigenvalue $=1.44$ ); these two components accounted for $67 \%$ of the total variance of the data set. The scree test, which showed that there were some bending points at two components, further verified the number of dimensions. Based on this initial analysis, the author tried several rotation methods to determine which factors loaded on each of the two dimensions. The Varimax rotation method, which best revealed the underlying relationship, was chosen eventually. As can be read from Table 2, all factor loadings reach the acceptable level of 0.3 (Nunnally, 1978), with most of them exceeding 0.7. This means that no factor in the proposed framework should be eliminated since every item fit into one of the two components (all factor loadings $\geq .30$ ). The analysis also showed that the items for each component loaded unambiguously.

The major difference between the analysis result and the proposed model was the number of dimensions: the 12 factors clustered into two components rather than four. Closer investigation indicated that the second component actually included all three factors but the last one in the 'Privacy and Security' dimension, and the first component included all the other factors. Thus, the author named the first component the 'Course Instruction' dimension, which related to different aspects (e.g., reputation, design quality, instructor sociocommunicative style) of the e-learning course, and kept the last component as the 'Privacy and Security' dimension. To examine the internal reliability of each dimension (i.e., Course Instruction, Privacy and Security), Cronbach's alpha was calculated on each dimension, and the alpha coefficients were 0.91 and 0.90 , respectively. According to Nunally (1978), an alpha of 0.50 or higher indicates a sufficient level of internal reliability. Therefore, based on these results, it may be concluded that these two dimensions represented different aspects or features of an e-learning course to promote student trust. 
Table 2. Rotated Component Matrix of the Trust-Inducing Factors $(N=361)$

\begin{tabular}{|c|c|c|c|}
\hline \multirow{2}{*}{ Dimensions } & \multirow{2}{*}{ Features } & \multicolumn{2}{|c|}{ Component } \\
\hline & & 1 & 2 \\
\hline \multirow{8}{*}{$\begin{array}{c}\text { Course } \\
\text { Instruction }\end{array}$} & $\mathrm{C} 1$ - Prior positive experience & .515 & \\
\hline & $\mathrm{C} 2$ - Good reputation & .733 & \\
\hline & C3 - High information and design quality & .894 & \\
\hline & C4 - Contact details & .810 & \\
\hline & C5 - Instructor assertiveness & .632 & \\
\hline & C6 - Instructor responsiveness & .599 & \\
\hline & C7 - A sense of care and community & .801 & \\
\hline & C8 - Reliable and timely access & .760 & \\
\hline \multirow{3}{*}{$\begin{array}{c}\text { Privacy \& } \\
\text { Security }\end{array}$} & P1 - Privacy and security policy statement & & .835 \\
\hline & P2 - Security mechanisms & & .897 \\
\hline & P3 - Third-party privacy assurance or standard & & .883 \\
\hline
\end{tabular}

Evaluating Relative Importance of Dimensions

Figure 1. Boxplot of the Median Ratings of the Items within Each Dimension (the Circles are Outliers)

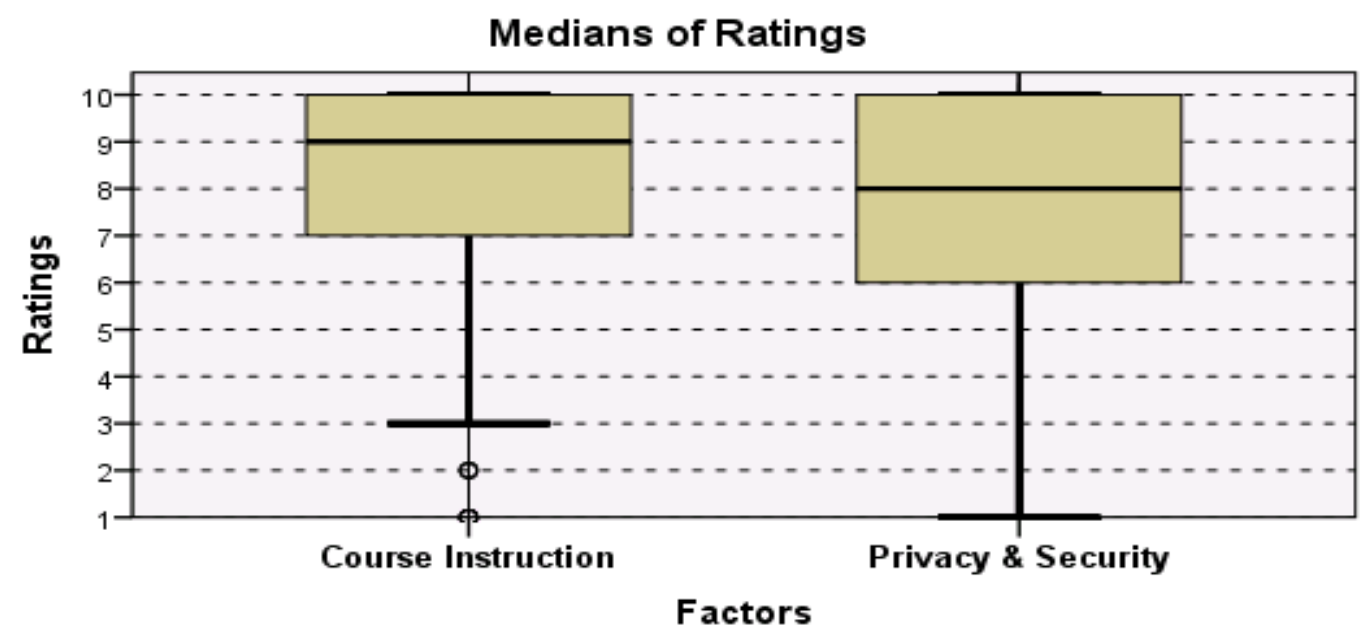

To investigate the relative magnitudes in ratings among the survey items that fell within each of the two dimensions, the median rating across those items was determined for each of the 361 respondents. The median is the appropriate index of central tendency for ordinal data. Figure 1 presents boxplots of the medians of those ratings for each of the two dimensions. It shows that both medians exceed 5, but the median for the Course Instruction 
dimension is higher than that for the Privacy and Security dimension (9 vs. 8). The results of the Kruskal-Wallis test with pairwise comparisons showed significant differences between the two dimensions ( chi-square $=14.33, \mathrm{df}=1$, $p<0.001)$. These data suggest that every factor contributed to the value of the respondents' evaluations, but the Privacy and Security dimension was rated as slightly less important than the Course Instruction dimension.

\section{Conclusion}

As Web-based course delivery continues to emerge and thrive as a legitimate alternative to classroom instruction, educational institutions and online instructors face the challenge of building and sustaining student trust in e-learning. The present study represents an attempt to address the challenge by identifying the social and technical factors that can likely induce or influence students' perception about the trustworthiness of an e-learning course and integrating the factors into a socio-technical framework that can be empirically validated.

The findings of the study are summarized as follows. First, the confirmatory factor analysis has suggested that two underlying dimensions, Course Instruction and Privacy and Security, exist among the 12 trust-inducing factors. Second, although all 12 factors were found to contribute to the respondents' perception of the trustworthiness of an e-learning course, the two identified dimensions differed in terms of their relative importance to inducing student trust. The Course Instruction dimension was rated about $10 \%$ higher than the Privacy and Security dimension. This suggests that the social and course design factors (e.g., reputation, design quality, instructor sociocommunicative style), when used effectively, can help overcome students' privacy and security concerns for an e-learning course.

The present study makes at least two important contributions to the field. First, the study identifies 12 trust-inducing factors from the literature and provides empirical evidence and indicative support for their importance in affecting students' trust in e-learning. Second, the study extends the confirmatory factor analysis (CFA) to a new application area of trust evaluation in e-learning. While the e-learning evaluation has been traditionally limited to the evaluation of teaching effectiveness, CFA offers an accessible analysis method for researchers to investigate and promote e-learning from a unique angle.

One line of future research is in relation to the additional factors that could be continuously added to the socio-technical framework. For example, Sousa et al. (2006) have identified that the inclusion of a face-to-face opportunity could help foster trust in online relationships. Future research may also explore the intersection of e-learning and disability, especially investigating how to establish a trustworthy e-learning environment for students with disabilities, and ultimately improving the online learning experience of students with a wide variety of barriers. 


\section{References}

Akhter, F., Buzzi, M. C., Buzzi, M., \& Leporini, B. (2009). 'Conceptual framework: How to engineer online trust for disabled users.' In Proceedings of the 2009 IEEE/WIC/ACM International Joint Conference on Web Intelligence and Intelligent Agent Technology-Volume 03 (pp. 614-617). IEEE.

Al-Ani, B., D. Redmiles, C.R. de Souza, R. Prikladnicki, S. Marczak, F. Lanubile, \& F. Calefato. (2013). 'Trust in virtual teams: theory and tools'. In Proceedings of the 2013 Conference on Computer Supported Cooperative Work Companion (pp. 301-306). ACM.

Allen, I.E. \& J. Seaman. (2013). Changing course: Ten years of tracing online education in the United States. San Francisco: Babson Survey Research Group and Quahog Research Group, LLC.

Anwar, M., \& Greer, J. (2012). 'Facilitating trust in privacy-preserving e-learning environments'. IEEE Transactions on Learning Technologies, 5(1), 62-73.

Bansal, G., Zahedi, F., \& Gefen, D. (2008). 'The moderating influence of privacy concern on the efficacy of privacy assurance mechanisms for building trust: A multiple-context investigation.' In Proceedings of Twenty Ninth International Conference on Information Systems. Association for Information Systems.

Bulach, C. (1993). 'A measure of openness and trust'. People and Education, 1: 382392.

Casaló, L.V., C. Flavián, \& M. Guinalíu. (2008). ‘Trust in virtual communities'. In G. Putnik \& M. Cruz-Cunha (eds.), Encyclopedia of Networked and Virtual Organizations, 1697-1704. Hershey: IGI Global.

Cheung, M.K. \& M.K.O. Lee. (2006). 'Understanding consumer trust in internet shopping: A multidisciplinary approach'. Journal of the American Society for Information Science and Technology, 57(4): 479-492.

Curzon-Hobson, A. (2002). A pedagogy of trust in higher learning. Teaching in higher education, 7(3), 265-276.

Ghosh, A.K., T.W. Whipple, \& G.A. Bryan. (2001). 'Student trust and its antecedents in higher education'. Journal of Higher Education, 72(3): 322-340.

Grandison, T. \& M. Sloman. (2000). 'A survey of trust in internet applications'. Communications Surveys \& Tutorials, IEEE, 3(4): 2-16.

Ha, S. \& L. Stoel. (2009). 'Consumer e-shopping acceptance: Antecedents in a technology acceptance model'. Journal of Business Research, 62(5): 565-571.

Hashem, M.E. (2011). 'The role of new information technology in education and development: A case study of building trust in distance education.' International Journal of Arts \& Sciences, 4(11): 387-398.

Jackson, D.L., J.A. Gillaspy Jr, \& R. Purc-Stephenson. (2009). 'Reporting practices in confirmatory factor analysis: An overview and some recommendations'. Psychological methods, 14(1): 6.

Jaeger, P. T., \& Xie, B. (2009). 'Developing online community accessibility guidelines for persons with disabilities and older adults.' Journal of Disability Policy Studies, 20(1), 55-63.

Jarvenpaa, S.L., N. Tractinsky, \& M. Vitale. (2000). 'Consumer trust in an internet store'. Information Technology and Management, 1: 45-71.

Koohang, A. \& K. Harman. (2005). 'Open source: A metaphor for e-learning.' Informing Science Journal, 8: 75-86. 
Kramer, R.M. (1999). 'Trust and distrust in organizations: Emerging perspectives, enduring questions.' Annual Review of Psychology, 50(1): 569-598.

Liu, Y. \& Y. Wu. (2010). 'A survey on trust and trustworthy e-learning system'. In Proceedings of 2010 International Conference on Web Information Systems and Mining (pp. 118-122). IEEE.

Luhmann, N. (2000). 'Familiarity, confidence, trust: problems and alternatives.' In D. Gambetta (ed.), Trust: Making and breaking cooperative relations, 6: 94-107. New York: Basil Blackwell.

Nicolaou, A. I., \& McKnight, D. H. (2006). 'Perceived information quality in data exchanges: Effects on risk, trust, and intention to use.' Information Systems Research, 17(4), 332-351.

Nunnally, J. C. (1978). Psychometric Theory. 2nd ed., Englewood Cliffs: McGrawHill.

Raitman, R., Ngo, L., Augar, N., \& Zhou, W. (2005). Security in the online e-learning environment. In Proceedings of the Fifth IEEE International Conference on Advanced Learning Technologies (pp. 702-706). IEEE.

Song, J., \& Zahedi, F. (2007). 'Trust in health infomediaries.' Decision Support Systems, 43(2), 390-407.

Sousa, S., D. Lamas, \& B. Hudson. (2006). 'Understanding learner's trust within an online distance learning context'. In Proceedings of the IADIS International Conference e-Society (pp.24-28).

Wang, Y.D. \& H.H. Emurian. (2005). 'An overview of online trust: Concepts, elements, and implications'. Computers in human behavior, 21(1): 105-125.

Wooten, A.G. \& J.C. McCroskey. (1996). 'Student trust of teacher as a function of socio-communicative style of teacher and socio-communicative orientation of student'. Communication Research Reports, 13(1): 94-100. 